\title{
Magnetic Alignment of Microsteel Fibers as Strategy for Reinforcing UHPFRC
}

\author{
Lukas Ledderose $^{1}$, Abtin Baghdadi ${ }^{1}$, and Harald $\mathrm{Kloft}^{1}$ \\ ${ }^{1}$ Technische Universität Braunschweig, Institute of Stuctural Design (ITE)
}

\begin{abstract}
The objective of this paper is to provide an insight into current basic research at ITE for the production of resource-efficient components through the controlled, automated magnetic distribution and alignment of steel fibers in UHPFRC (Ultra-High Performance Fibre-Reinforced Concrete). The method for distributing and aligning steel fibers in UHPFRC is based on the physical phenomenon of magnetism. Since steel fibers are ferromagnetic, magnetic fields can selectively change their position in the fresh concrete and align them according to the force flow and the maxim "form follows force". The magnetic fiber alignment (MFA) process developed on this principle combines the capabilities of digital and automized component manufacturing with the potential of targeted fiber alignment to increase the material efficiency of UHPFRC. It is highlighted at four levels:

At the material level, studies were conducted on the composite properties of different brandnew and recycled microsteel fibers (MSF), formwork designs suitable for the MFA process were developed, flux densities of different magnets were simulated with special software solutions and measured in practice, and an end effector was fabricated that was implemented on 3- and 6-axis kinematics. At the process level, the interaction of the main parameters of the MFA process was evaluated by visual analysis on transparent glucose syrup-based solutions, and series of specimens were analyzed by micro-CT scans. At the component level, centric tensile tests were performed on a wide variation of dog-bones to provide an assessment of the potential increase in tensile performance of UHPFRC by the MFA process. At an economic and environmental evaluation level, the results from the tensile tests were used to assess and quantify the potential savings from reducing the fiber content and using recycled steel fibers.
\end{abstract}

Keywords: UHPFRC, magnetic fiber alignment, sustainability

Conference presentation video: https://doi.org/10.5446/56111

\section{Introduction}

Lightweight and thin concrete components made of UHPFRC require tight manufacturing tolerances and high material efficiency due to their low wall thickness and filigree nature. This can be achieved in terms of the material quality of the concrete matrix and the fiber content. In terms of fiber distribution and orientation, the precision and efficiency is missing: In expectation of a uniform distribution of fiber contents in the component, the microsteel fibers (MSF) are added to the matrix during the mixing process and poured into the forms as a complete mixture. To ensure a certain concentration of effective fibers in UHPFRC components, the overall quantity of all fibers is increased, with the consequence of poorer workability of the fresh concrete. Thus, a considerable amount of microsteel fibers that are not effective for bearing capacity are used inefficiently. In the course of the development of UHPFRC, MSF with a tensile strength of at least $2000 \mathrm{MPa}$ in particular have proven to be effective due 
to their strong bond with the concrete matrix [1].

The goal of the research described is to provide the foundation for the production of resource-efficient components using controlled, automated magnetic distribution and alignment of MSF in UHPFRC. In principle, three strategies for a more sustainable use of MSF can be pursued with the MFA process. First, starting from a given fiber content, an increase in ultimate load can be achieved by transferring the individual fibers into a more efficient position and orientation. Second, while maintaining a desired material strength, the fiber content can be reduced through targeted orientation. Third, the higher strengths of the fiber-matrix system achieved by the MFA process provide the opportunity for a leaner design of UHPFRC components and thus for a reduction in matrix and deadweight. Which of these three goals should be pursued by the MFA process must be decided on a case-by-case basis.

Extensive research on the magnetic alignment of MSF has been conducted at ITE over the past decade. For example, UHPFRC components have already been developed in projects of the DFG Priority Program 1542 "Concrete Light" [2], which were treated with the MFA process in first probing tests [3]. In addition, studies and experiments on the topic of magnetic fiber alignment in UHPFRC have been continuously conducted at ITE since 2014. These investigations addressed key aspects of this research project and provided concrete indications on the potentials of automized magnetic alignment and distribution of MSF. In particular, the influence of different magnetic fields on the alignment and movement of MSF was investigated experimentally in small test specimens. For this purpose, different gels were used in addition to the UHPC matrix, which, as transparent concrete substitutes, allowed direct observation of the effects. Other published preliminary investigations dealt with the automation of more complex reinforcement structures [4,5]. For example, robotic path-based modeling of intersecting fiber strands was investigated as they could be reasonably arranged in the tension zone of biaxially flexurally stressed slabs [6].

\section{Materials and applications}

\section{Matrix}

The process of magnetic alignment of MFA in UHPFRC places specific requirements on the matrix, particularly with regard to its composition and workability. As in previous investigations [7], a fine-grained concrete based on the ready-mix NANODUR® Compound 5941 gray developed by Dyckerhoff was used in these component tests (Tab. 1). The used formulation showed a high reproducibility of the rheological properties of the fresh concrete and the mechanical properties of the hardened UHPC (Tab. 2).

Table 1. Mix design of used UHPC

\begin{tabular}{|l|l|}
\hline Ingredient & Weight $\left[\mathbf{k g} / \mathbf{m}^{3}\right]$ \\
\hline NANODUR® Compound 5941, grey & 1100 \\
\hline Quartz sand H33 & 1012 \\
\hline Superplasticizer (GRACE ADVA® Flow 375) & 21 \\
\hline Shrinkage reducer (GRACE Eclipse® Floor) & 7 \\
\hline Water & 159 \\
\hline
\end{tabular}


Table 2. Material properties of used UHPC

\begin{tabular}{|l|l|}
\hline Characteristic & Mean value \\
\hline cube compressive strength $(\mathrm{I}=100 \mathrm{~mm})$ & $120 \mathrm{MPa}$ \\
\hline Uniaxial tensile strength $(\mathrm{min})$. & $3 \mathrm{MPa}$ \\
\hline Modulus of elasticity & $45 \mathrm{GPa}$ \\
\hline
\end{tabular}

\section{Microsteel fibers (MSF)}

MSF are particularly tightly bound into the very dense, strong and homogeneous structure of the fine-grained UHPC matrix. This allows high bond stresses to be transferred. In addition, the ductilizing effect of the fibers is based on the fact that in the case of cracks in the matrix, the bond friction between the matrix and the fibers is overcome without the fibers themselves cracking [8].

MSF of different lengths $(4,6,8$ and $11 \mathrm{~mm})$ and different diameters $(0.13$ and $0.17 \mathrm{~mm})$ and a fiber mix (MSF Mix) consisting of the fiber types MSF 4, 6 and 8 in equal weight proportions were analyzed and examined in experimental component tests for their suitability for the MFA process. All MSF were manufactured in accordance with DIN EN 10025-2 [9] as a hot-rolled product from mild steels in wet drawing processes and are certified in accordance with DIN EN 14889-1 [10]. They were brass coated for increased corrosion resistance. Due to the high impermeability of the UHPC structure, however, the near-surface corrosion of the fibers has no adverse effect on the durability of the components anyway [11].

The manufacturing process accounts for the very high tensile strength. Own investigations of the maximum tensile strength at fiber break resulted in values of $3400 \mathrm{MPa}$ for fibers of diameter $0.13 \mathrm{~mm}$ and over $3900 \mathrm{MPa}$ for fibers of diameter $0.17 \mathrm{~mm}$. This high tensile strength compared to rebars (340 to $540 \mathrm{MPa}$ ) results from work hardening, which takes place during cold forming in the wire drawing process, accompanied by a simultaneous decrease in toughness.
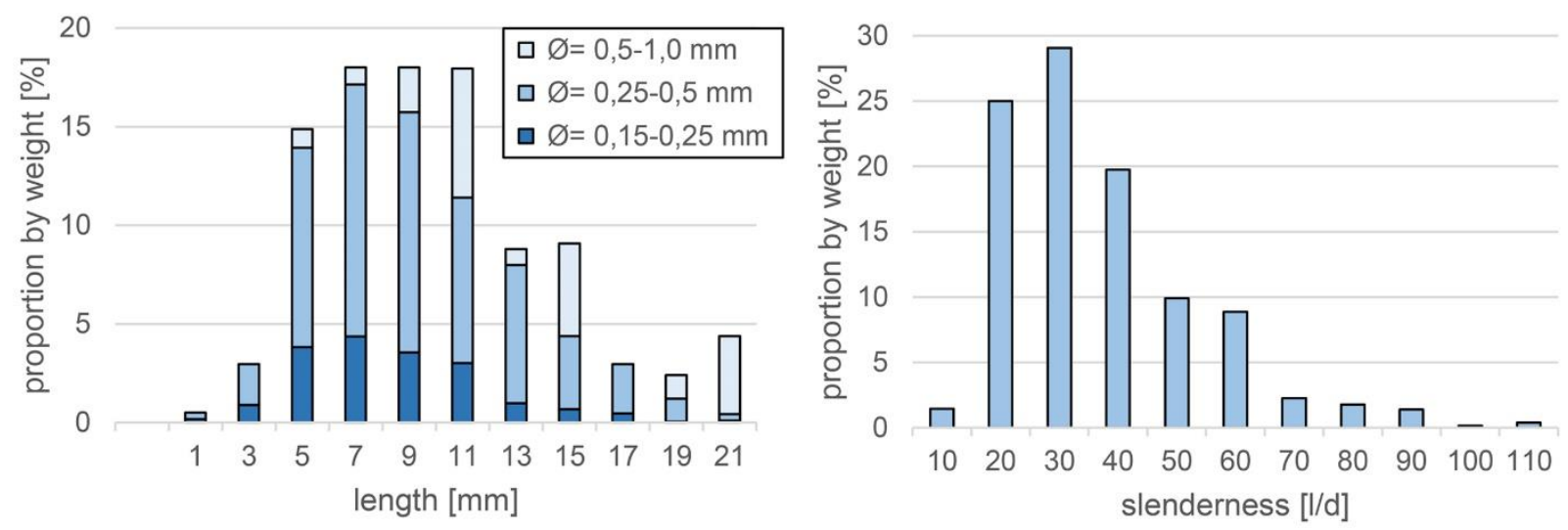

Figure 1. Distribution of lenghts and diameters (fiber type Rec) (left);

$$
\text { Distribution of slenderness (fiber type Rec) (right) }
$$

In addition, recycled fibers (fiber type Rec) were also investigated and used. The possible application as concrete reinforcement of this so-called srap-tire steel has already been investigated in some approaches $[12,13]$. The fibers used here were provided by Genan, a company specialized in recycling scrap tires [14]. These uncertified fibers were inconsistent in geometry, some had adhesions of rubber, and most were not brass coated. Their tensile strengths were determined in own tensile tests and were $3800 \mathrm{MPa}$ on average. 
To determine the distribution of their geometrical properties such as length, diameter, slenderness and straightness, a sample weighing 10 grams and consisting of about 2500 individual fibers was examined. Figure 1 (left) shows the distribution of lengths and diameters, Figure 1 (right) the distribution of fiber slenderness.

Table 3 shows comparatively the most important geometrical properties of all fiber types. Three correlations between fiber geometry and fiber number should be pointed out here, each related to the same sample weight:

- As can be seen in the comparison between the fiber types MSF 4,6 and 8, the fiber slenderness, i.e. the ratio of fiber length to fiber diameter, increases for the same diameter but rising fiber length. At the same time, the number of individual fibers is reduced.

- The fiber type Rec shows a comparatively low number of individual fibers and a small total surface area due to its on average quite short and thick fibers.

- Compared with the $0.17 \mathrm{~mm}$ thick MSF 11 , the $0.13 \mathrm{~mm}$ thick MSF 8 shows, despite comparable slenderness, a more than 2.3-fold higher number of individual fibers and a total surface area (contact area with the matrix) that is about one third larger.

Table 3. Comparison of the geometric properties of MSF

\begin{tabular}{|c|c|c|c|c|c|}
\hline fiber type & $\begin{array}{l}\text { fiber length I } \\
{[\mathrm{mm}]}\end{array}$ & $\begin{array}{l}\text { diameter d } \\
{[\mathrm{mm}]}\end{array}$ & $\begin{array}{l}\text { Slenderness } \\
(\mathrm{I} / \mathrm{d})\end{array}$ & $\begin{array}{l}\text { count per g } \\
\text { [pcs.] }\end{array}$ & $\begin{array}{l}\text { surface per } \mathbf{g} \\
{\left[\mathrm{cm}^{2}\right]}\end{array}$ \\
\hline MSF 4 & 4 & 0,13 & 30,1 & 2400 & 39,2 \\
\hline MSF 6 & 6 & 0,13 & 46,2 & 1600 & 39,2 \\
\hline MSF 8 & 8 & 0,13 & 61,5 & 1200 & 39,2 \\
\hline MSF Mix & $5,3(\varnothing)$ & 0,13 & $42,5(\varnothing)$ & 1734 & 39,2 \\
\hline MSF 11 & 11 & 0,17 & 64,7 & 510 & 30,0 \\
\hline $\operatorname{Rec}$ & $6,3(\varnothing)$ & $0,32(\varnothing)$ & $36,9(\varnothing)$ & 257 & 15,0 \\
\hline
\end{tabular}

Two different fiber types were selected for the centric tensile tests shown below: First, MSF 8 , which had proven to be the best performing fiber type within the group of MSF mentioned above. Its advantages, resulting from the high number of slender individual fibers with a large total surface area in relation to the sample weight, was also proven in bending tensile tests. Secondly, the fiber type Rec, which is geometrically inferior to MSF 8 but impresses with its economic and ecological benefits.

\section{Magnets}

The selection of the magnets was essentially based on two methods: The analysis of different magnetic fields using a FEMM software solution (Finite Element Method Magnetics, [15]) and the real measurements on selected single magnets and magnet combinations.

With the aid of the FEMM simulations, it was possible to visualize and evaluate the complex magnetic field geometry of both individual permanent magnets and their combinations as well as electromagnets. Although the simulations could be used for the specific selection of suitable magnets, the real magnetic flux densities had to be validated due to inaccuracies resulting from the simplified simulation in two-dimensional space. Thus, measurements in 2millimeter steps up to $30 \mathrm{~mm}$ at and between the magnet poles were performed with a calibrated magnetometer. The exclusively used sintered NdFeB - magnets (neodymium-ironboron) are currently the strongest permanent magnets [16]. They are characterized in particular by a very high energy density in relation to their volume and are classified according to their maximum energy product, which refers to the powers of the magnetic flux per unit volume (N 35 to $\mathrm{N} 52$ ). 

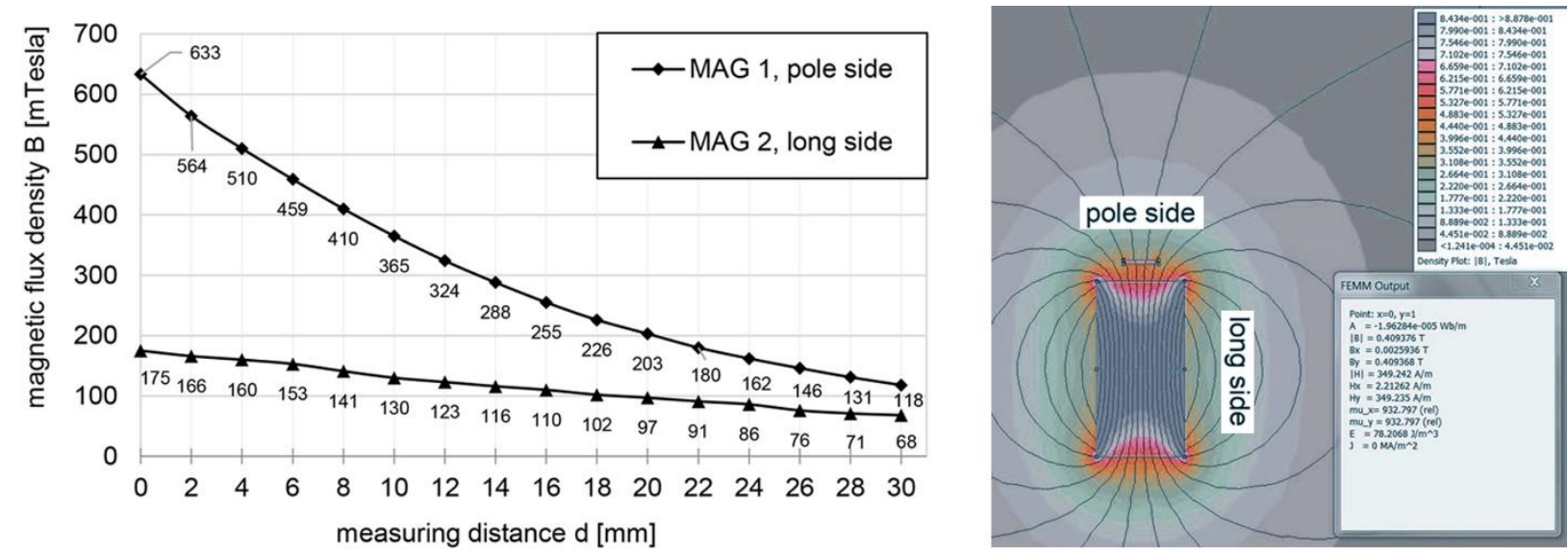

Figure 2. Flux density of MAG 1 and MAG 2 (left); Magnetic field lines of MAG 1 (right)

Figure 2 (left) shows the rapid decrease of the magnetic flux density with increasing distance to the magnet surfaces at the example of the two NdFeB magnets MAG 1 and MAG 2 used here. Figure 2 (right) illustrates the lower flux density between the poles (long side) and the elongated course of the field lines here. In contrast, the flux density is highest directly at the poles, while the field lines are more curved.

\section{End effectors}

Various magnets were applied in the research project, which were attached to individual holders (end effectors) on different robot models and CNC systems. Figure 3 shows the end effector used here. It basically consisted of a spring-mounted structure made of aluminum and 3D-printed plastic parts. The stiff parallelogram mechanism of the suspension allowed a defined contact pressure of the magnets, which was controlled by hydraulic shock absorbers. It was capable of alternating two different magnets and corresponding magnetic field geometry. A pneumatically initiated swiveling movement was triggered by a command stored in the machine code, thus enabling the use of two magnets without a conventional tool change. One of the two magnets was attached to a DC motor, which provided continuous and controllable rotation of the MAG 2 about its longitudinal axis when required. For the experiments shown here, the end effector was equipped with the MAG 1 and MAG 2 magnets; the rotation function was not used for the purely linear movements carried out here.

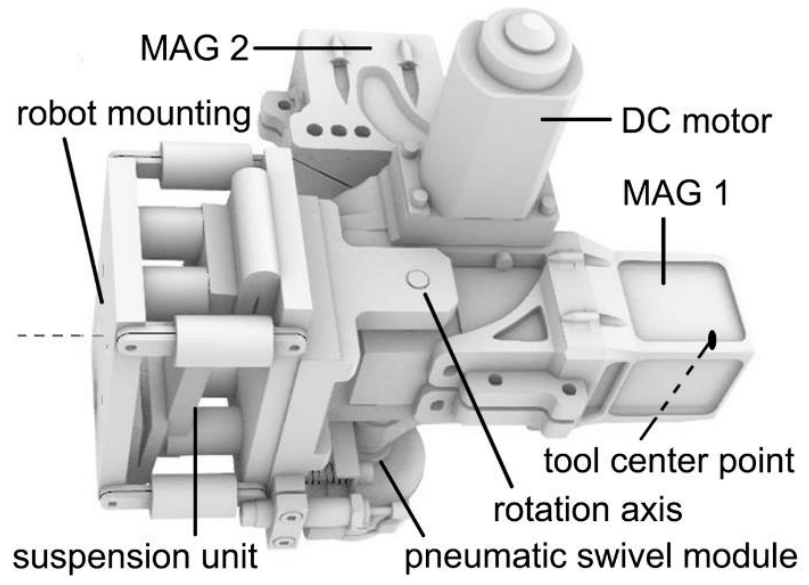

Figure 3. Visualization of the end effector with integrated magnet changer 


\section{Experiments}

\section{Efficiency increase of the fiber content}

Decisive for the efficiency of the individual MSF in the UHPFRC matrix are the fiber geometry, the bond behavior and the local distribution and orientation [17, 18]. In particular, only that fiber portion is relevant for the transmission of tensile forces that is located in a component parallel or in a moderate deviation to the direction of the occurring tensile stresses. Also, only those locations are of importance where tensile stresses actually occur [19]. Thus, in a component with random distribution of fibers, not even half of the fibers used are relevant for the transmission of tensile forces. They are the only fibers that lead to the required loadtransmitting crack bridging in the cracked state of the component, as well as to the resulting failure indication and possible increase in post-crack load-bearing capacity [20]. In contrast, fibers are not effective for the transmission of compressive forces, and the fiber content that is oriented approximately in parallel to the compressive forces occurring in a component remains ineffective [21].

Figure 4 (left) shows the probability of a randomly oriented single fiber deviating from a tensile trajectory. For a small deviation of $0-15^{\circ}$ it is only $3.4 \%$. In the range of moderate deviations it is $10.0 \%\left(15-30^{\circ}\right)$ and $15.9 \%\left(30-45^{\circ}\right)$. On the one hand, this geometric correlation between fiber orientation and fiber effectiveness illustrates the large unused fiber content of about $70 \%$, which can be omitted in components with clear tensile load directions. However, it also shows the narrow spectrum that must be maintained for a directed fiber alignment. Figure 4 (right) clearly shows the difference between a magnetically aligned fiber strand and a random fiber alignment in relation to a defined tensile direction. While the probability distribution of the fiber alignment parallel to the main tensile direction $\left(=0^{\circ}\right)$ strongly decreases in the case of a random fiber alignment (blue dashed line), the predominant fiber portion of a magnetically treated specimen lies in the range of $0-45^{\circ}$ (red line), which is relevant for the transmission of tensile forces. In addition, the random, average fiber orientation without reference to a main tensile direction is also shown (black dotted line).
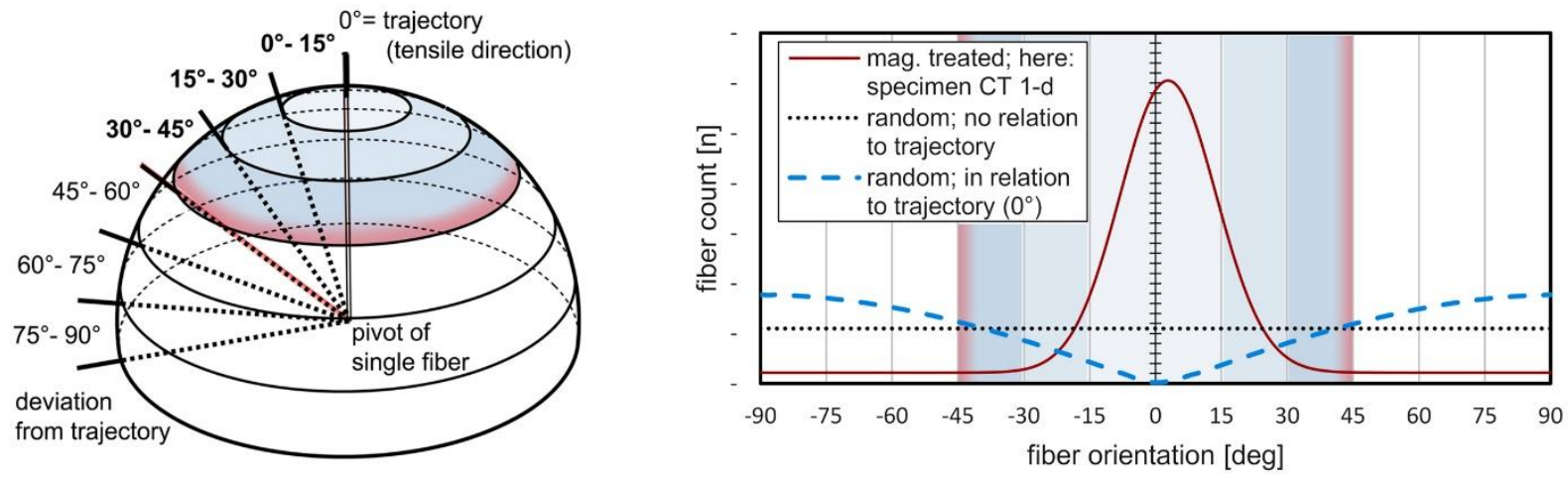

Figure 4. Deviation of fiber orientation from the trajectory (left);

Distribution of fiber orientation relative to the trajectory (right)

\section{Bond behavior}

The design principle of fiber-reinforced concrete differs fundamentally from the fiber-based design principles of nature and the construction methods derived from it, such as fiberreinforced plastics. While the tensile strengths of these structures are largely based on long, thin fibers oriented in the direction of tension, the composite behavior between fibers and matrix plays a crucial role in short-fiber composites such as UHPFRC. There are two reasons for reinforcing concretes with short fibers. On the one hand, the mixing process of fiber- 
reinforced concretes requires a certain dimensional stability of short fibers and their uniform distribution in the matrix; on the other hand, they are mainly required for ductile material behavior, which is achieved by pulling them out of the cracked matrix rather than by tearing them apart. Here, the bond behavior in interaction with the fiber properties as well as the pullout direction of the fibers is decisive [22, 23].

In the case of straight fiber pull-out, micro-interlocking and adhesion provide the largest contributions to the maximum transmittable fiber tensile forces, friction plays a minor role. Due to fiber deformation at the deflection point, even higher tensile forces can usually be transmitted by the fiber in the case of an angled fiber pull-out. However, the formation of breakout cones at larger angles can affect the deformation capacity of the UHPFRC and lead to a more brittle mode of failure [24]. To gain deeper insight into the composite behavior of the fiber-matrix combination used here, pull-out tests were performed on straight and angled fibers.
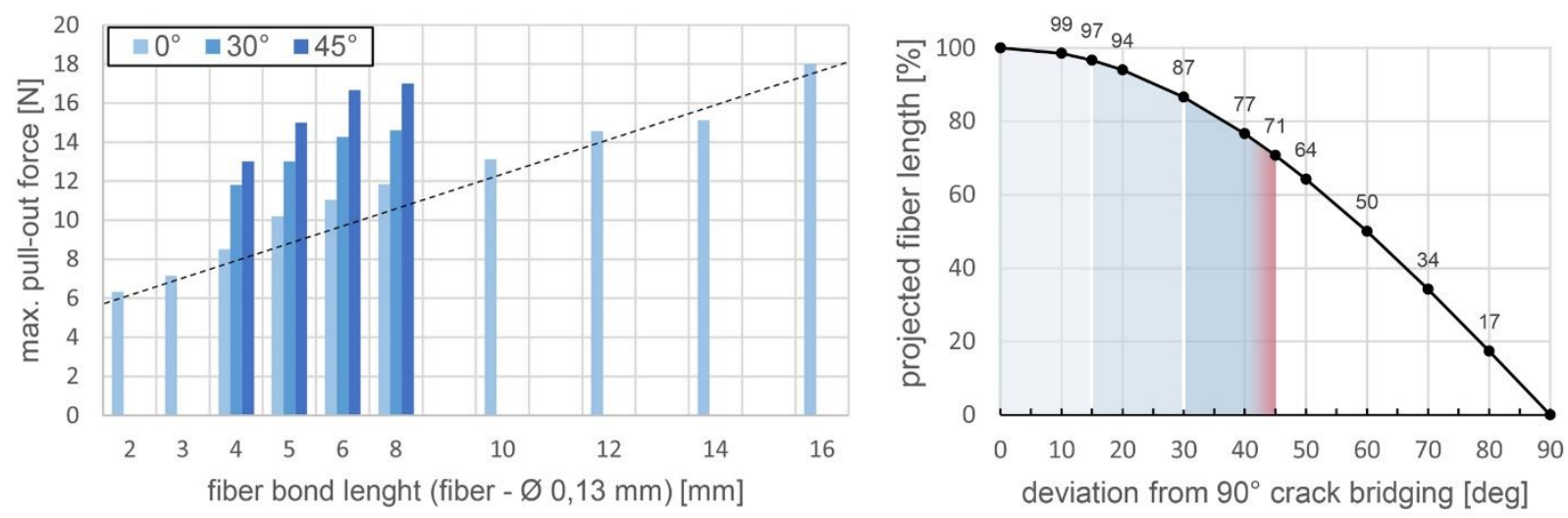

Figure 5. Results of pull-out test of individual fibers (left);

Fiber orientation and probability of crack bridging (right)

Figure 5 (left) shows the maximum pull-out forces in relation to the bond length as well as the angle of fiber pull-out. The fiber pullout forces at $30^{\circ}$ and $45^{\circ}$ angles and a bond length of 4 $\mathrm{mm}$ increased by $38 \%$ and $52 \%$, with increasing damage to the matrix at the pullout location.

However, as shown in Figure 5 (right), increasing deviation of the fiber orientation parallel to the main tensile direction is coupled with a shortening of the projected fiber length and a decrease in the probability of crack bridging. The ratio of the projected length to the bond length is called the fiber orientation coefficient $\eta$. While the projected fiber length is hardly reduced at moderate deviations from the main tensile direction, it already drops to $50 \%$ at a deviation of $60^{\circ}$.

The two counteracting effects on fiber effectiveness can therefore partially neutralize each other. Although this expands the range of effective fiber orientation, it makes it more difficult to specify a narrow fiber angle spectrum. However, the tensile load-bearing behavior of UHPFRC cannot be directly derived from the bond behavior of single fibers, since further effects from scattering of the local fiber distribution and the bond behavior of fiber groups cannot be quantified in a universally valid way [25]. Nevertheless, it is a general principle that a fiber orientation parallel to the tensile direction causes an almost linear force decrease in the fiber pull-out phase, and a fiber inclination up to about $45^{\circ}$ keeps the tensile forces longer due to fiber redirection - with increased damage to the matrix. A fiber inclination of $45^{\circ}$ and above makes crack-bridging force transmission more difficult and faces the risk of being abruptly terminated by fiber rupture [26].

\section{Process parameters}

The analyses presented above demonstrate that, in addition to the selection of a suitable 
fiber-matrix combination, fine adjustment of the process parameters of the MFA process is also necessary to achieve a significant increase in the performance of UHPFRC components.

These process parameters were investigated at ITE using two main experimental methods.

A transparent substitute for the liquid UHPC matrix based on glucose syrup was developed to allow immediate visual control of the influence of the magnetic fields on the movement of the fibers. The formulation was adapted to the consistency of the liquid UHPC using modified penetration tests of needles according to Vicat [27] and in spreading tests with the Hägermann cone. Although these two test methods are originally used for the determination of the setting time and yield stress, they could serve here for an approximation of the substitute to the used UHPC: The vacuum-deaerated mixture of glucose syrup $43^{\circ}$ and $45^{\circ}$ in the mixing ratio $23: 77$ corresponded to the UHPC matrix at a temperature of $20^{\circ} \mathrm{C}$ in both test methods with a deviation of penetration time (weight: $300 \mathrm{~g}$, steelball, diameter: $10 \mathrm{~mm}$; travel: $40 \mathrm{~mm}$ ) and slump flow spread (meassurement after $8 \mathrm{~min}$.) of $\pm 4 \%$ each. This substitute replaced a previously used ultrasonic gel based hydrogel and could be used to to narrow the process parameters.

The second method was based on the capabilities of 3D image processing. In a parameter study on 27 UHPFRC specimens, the three most important process parameters of travel speed, magnetic field strength and component thickness were investigated. Micro-computed tomography $(\mu C T)$ was used to acquire the MSF in the cuboid specimens $(40 \times 40 \times 15 / 20 / 30$ $\mathrm{mm}$ ). The use of the Amira-Avizo 3D [28] and Fiji [29] software solutions allowed the accurate and automated analysis of the MSF in terms of their distribution, location and orientation in the specimens, allowing the interaction of the three process parameters to be assessed and quantified. Special attention was paid to the evaluation of the mentioned fiber orientation coefficient, which describes the influence of the orientation on the effectiveness of the fiber in a certain axial direction [30], as well as the fiber distribution along the cross-section of the specimens.

As mentioned, two magnets were used in the experiments: MAG 1 had dimensions of $40 \times$ $40 \times 80 \mathrm{~mm}$ and grade $\mathrm{N} 45$. The north and south poles of the magnet were located at the end of the long central axis, respectively. In a first step, its strong pole side was used to move the randomly distributed MSF from the specimen cross-section toward a cross-section side. The intensity of the fiber movements could be controlled with the travel speed of the end effector. With its edge length of $50 \mathrm{~mm}$, the cube magnet MAG 2 generates a broader magnetic field than the pole side of Mag 1. Its long side could be used in a second step to rotate the locally concentrated MSF into an angular range parallel to the formwork face. In this way, reinforcement layers could be designed in the tensile zones of specimens whose individual fibers, arranged along the tensile trajectories, lay in an angular range of $0^{\circ}-45^{\circ}$. In this way, reinforcement layers could be designed in the tensile zones of specimens whose individual fibers, arranged along the tensile trajectories, lay in an effective angular range of $0^{\circ}-45^{\circ}$. The angular range could even be limited to $0^{\circ}-15^{\circ}$ by adjusting the parameters, and the strands could be compacted down to a fiber content of $10 \%$ by volume (Figure 6 (left)). A numerical approach to include this fiber distribution, which is not nonhomogeneous across the cross section, in the calculation of the flexural strength is explained in [3, 31]. 

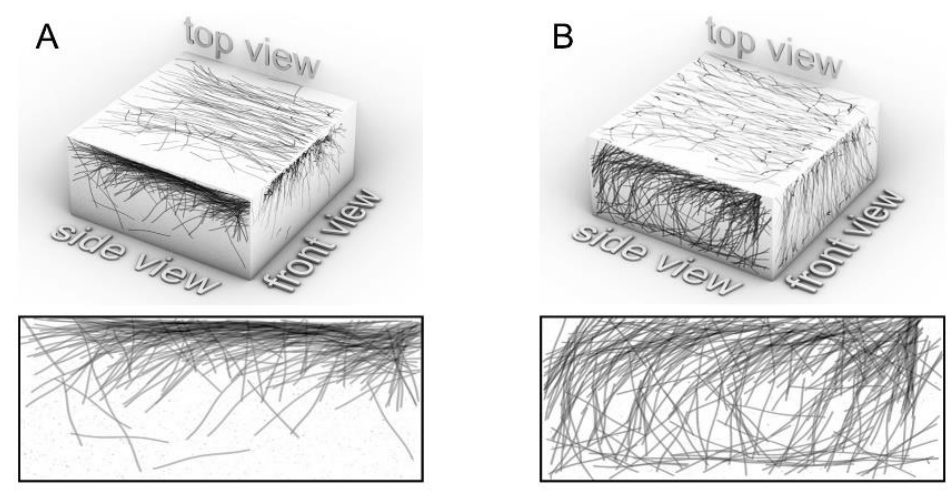

Figure 6. Visualization of $\mu \mathrm{CT}$ images of $\mathrm{A}$ : concentrated fiber strand (left);

B: fiber strand distributed over the entire cross-section (right)

For component thicknesses of or below $30 \mathrm{~mm}$, such as the dog-bones investigated, an alignment uniformly distributed over the cross-section was achieved with fiber angles deviating only moderately from the tensile direction (Fig. 6 (right)). By fine tuning the parameters of traverse speed, magnet spacing and magnet change, homogeneous and efficient fiber strands could be modeled, especially at higher fiber contents from $2.5 \%$ by volume. The gaps between parallel strands could be reduced to $20 \%$ of the magnet widths without pronounced mutual interference between the parallel strands during modeling. In these gaps, the formation of three-dimensional transverse ribs could be observed, which formed an arcor s-shaped bond between the strands depending on the path directions. Since the magnetic field strength of the used magnets at a distance of $30 \mathrm{~mm}$ is only about $39 \%$ (long side) or $19 \%$ (pole side) of the magnet surface (see Figure 2, left), a magnetic treatment on both sides is suitable for components with cross sections larger then $30 \mathrm{~mm}$.

\section{Production of the test specimens}

All UHPFRC mixtures were produced with a planetary mixer using a flat paddle mixer. The horizontal formworks were filled with shovels from above. In order to exclude the influence of a dominant flow direction and to achieve a fiber concentration as homogeneous as possible without local imperfections, overlapping portions of about $100 \mathrm{ml}$ each were poured in. After a five-minute venting period under low-frequency vibration, the formwork was closed with screws. This was followed by the automated MFA, also in a horizontal position, within a maximum of 35 minutes after the end of mixing. Hardening of all test specimens took place in an upright position at about $20^{\circ} \mathrm{C}$. They were stripped after 48 hours and stored in a moist place until they were tested after 28 days. For the consistency test, the target mini slump flow spread of $270 \pm 10 \mathrm{~mm}$ was checked with the Hägermann cone without shocks in parallel with the filling of the formwork. In case of deviations, the formworks were cleared and a new mix was prepared.

\section{Centric tensile tests}

The effect of near-surface fiber concentration can be used for components that are exposed to a one-sided bending load. For this, detailed experimental and numerical investigations have already been carried out at ITE [3]. However, in order to perform measurements cleaned from this effect regarding the actual tensile load capacities, an experimental setup for centric tensile tests was developed for UHPFRC components of small thickness. Figure 7 (left) shows the geometry of the dog-bones with a linear robot path (red dashed line), the articulated sliding supports on both sides for fixation during the tensile test (center), and the modular design of the formwork (right). The MFA procedure was carried out on one side with the formwork lying flat. In order to quantify the influence of the formwork edges on the fiber orientation and thus the expected increase in tensile strength described in [32], dog-bones of 
three different thicknesses were investigated. The tensile tests were performed on a tensile testing machine of the IAM, TU Braunschweig with a $50 \mathrm{kN}$ load cell (accuracy class 0.5 ISO $7500-1$ ) at a speed of $v=0.15 \mathrm{~mm} / \mathrm{min}$ and a measuring rate of about $10 \mathrm{~Hz}$. Machine force and the machine path were recorded.

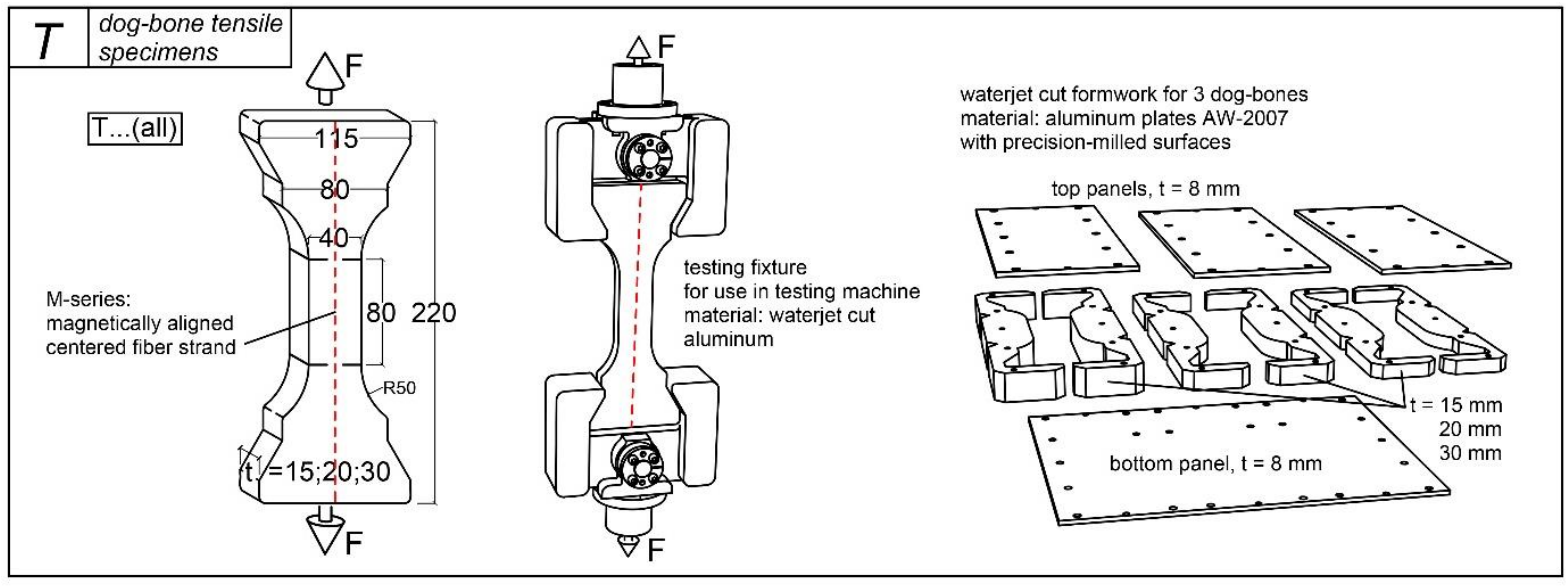

Figure 7. Shape and dimensions of the dog-bones (left), testing fixture (middle)

and construction of the formwork (right)

In this series of tests, a total of 24 dog-bones were tested. Three different thicknesses of dog-bones, four different fiber contents, two different fiber types, as well as dog-bones treated with the MFA process (M) and not treated (R) were varied. Table 4 lists all the specimens, as well as the results on the measurements performed. There are nine pairs of magnetically treated and non-treated dog-bones, whose measured values were directly compared in the lines increase [\%].

Table 4. Measured values from the tensile tests and comparative performance increase

\begin{tabular}{|c|c|c|c|c|c|c|c|c|c|c|c|}
\hline \multirow[b]{3}{*}{$T$} & \multirow{3}{*}{$\begin{array}{c}\text { reinforcement } \\
\text { quantity } \\
\text { [Vol\%] } \\
\text { and (type) } \\
\end{array}$} & \multirow{3}{*}{$\begin{array}{c}\text { type } \\
R \text { or } M^{* * I} \\
\text { increase } \\
M \text { to } R\end{array}$} & \multicolumn{9}{|c|}{ specimen thickness $\mathrm{t}[\mathrm{mm}]$} \\
\hline & & & \multicolumn{3}{|c|}{15} & \multicolumn{3}{|c|}{20} & \multicolumn{3}{|c|}{30} \\
\hline & & & $\begin{array}{c}\text { stress } \\
\sigma \mathrm{M} \\
{[\mathrm{MPa}]}\end{array}$ & $\begin{array}{c}\text { strain } \\
\varepsilon \mathrm{M} \\
{[\%]} \\
\end{array}$ & $\begin{array}{l}w \text { to } \\
(\varepsilon M) \\
{[k J]} \\
\end{array}$ & $\begin{array}{c}\text { stress } \\
\sigma M \\
{[\mathrm{MPa}]}\end{array}$ & $\begin{array}{c}\text { strain } \\
\varepsilon \mathrm{M} \\
{[\%]} \\
\end{array}$ & $\begin{array}{l}w \text { to } \\
(\varepsilon M) \\
{[k J]}\end{array}$ & $\begin{array}{c}\text { stress } \\
\sigma \mathrm{M} \\
{[\mathrm{MPa}]}\end{array}$ & $\begin{array}{c}\text { strain } \\
\varepsilon \mathrm{M} \\
{[\%]} \\
\end{array}$ & $\begin{array}{l}w \text { to } \\
(\varepsilon M) \\
{[k J]}\end{array}$ \\
\hline no.1- & \multirow{3}{*}{ 1,0 (MSF 8) } & $\mathrm{R}$ & 4,1 & 1,4 & 1,8 & 4,1 & 0,9 & 1,0 & 4,7 & 0,8 & 1,9 \\
\hline \multirow[t]{2}{*}{$2-$} & & $M$ & 4,3 & 1,7 & 2,1 & 4,2 & 1,4 & 2,5 & 5,8 & 1,3 & 3,8 \\
\hline & & increase [\%] & 7 & 21 & 14 & 1 & 55 & 159 & 23 & 63 & 97 \\
\hline 3- & 1,75 (MSF 8) & $\mathrm{M}$ & 7,6 & 1,9 & 4,0 & 6,4 & 1,3 & 6,9 & 6,3 & 1,6 & 6,1 \\
\hline 4- & 2,5 (MSF 8) & $\mathrm{M}$ & 8,0 & 1,1 & 2,4 & 9,3 & 2,6 & 2,1 & 7,7 & 1,5 & 5,5 \\
\hline $5-$ & \multirow{3}{*}{ 3,5 (MSF 8) } & $\mathrm{R}$ & 5,9 & 1,7 & 1,8 & 8,6 & 1,6 & 5,0 & 6,0 & 1,1 & 3,3 \\
\hline $6-$ & & $M$ & 14,3 & 2,0 & 6,2 & 14,5 & 2,5 & 11,5 & 15,5 & 3,5 & 29,9 \\
\hline & & increase [\%] & 42 & 18 & 237 & 68 & 56 & 128 & 157 & 218 & 800 \\
\hline $7-$ & \multirow{3}{*}{$4,5(\operatorname{Rec})$} & $\mathrm{R}$ & 6,0 & 1,2 & 1,7 & 7,0 & 0,8 & 1,8 & 7,0 & 1,1 & 5,1 \\
\hline \multirow[t]{2}{*}{$8-$} & & $M$ & 8,3 & 1,4 & 2,5 & 7,3 & 1,7 & 3,9 & 8,5 & 1,7 & 7,6 \\
\hline & & increase [\%] & 38 & 17 & 49 & 4 & 113 & 112 & 21 & 55 & 49 \\
\hline \multicolumn{3}{|c|}{24 specimens, e.g. name 1-a: T 1,0 R (t 15) } & \multicolumn{3}{|c|}{$a$} & \multicolumn{3}{|c|}{$\bar{b}$} & \multicolumn{3}{|c|}{ c } \\
\hline
\end{tabular}

Since the focus of the investigations was on the performance increase due to the MFA process, the tests were carried out with reduced measurement technology. Therefore, no further measurement data was collected with strain gauges or optical measurement. And since only one dog-bone type was produced at a time and the test results of UHPFRC specimens are generally subject to large scatter, no generally valid conclusions for construction practice can be derived from the measurements shown here. Nevertheless, there were the following clear 
trends:

- All specimens treated with the MFA procedure showed higher maximum tensile stress $(\sigma \mathrm{M})$, strain $(\varepsilon \mathrm{M})$ and work (w up to $\varepsilon M$ ) than the non-treated specimens at the same fiber content and MSF type.

- The measurements of the maximum tensile stresses did not show a clear correlation with the dog-bone thickness and thus of an influence of the formwork edges.

- The measured values of the series with the recycled fibers "4.5 (REC) M" are on average similar to those of the series "2.5 (MSF 8) M", which in this case would mean an increase of the fiber content of the Rec fibers by about $80 \%$ compared to the MSF 8.

- All measured values of the "2.5 (MSF 8) M" series are clearly above those of the "3.5 (MSF 8 ) R" series. Thus, in this case, at least $1 \%$ by volume, or a fiber content of $40 \%$, could be saved by the MFA process. This level of savings potential is also basically in agreement with the results of previous bending tensile tests [3].

Figure 8 (left, right) compares the series "1.0 (MSF 8) M", "1.0 (MSF 8) R", "3.5 (MSF 8) M" and "3.5 (MSF 8) R". The marked average max. tensile stresses of the respective series illustrate the increasing effect of the MFA process with increasing fiber content. The measured maximum tensile stresses of the "3.5 (MSF 8) M" series are higher than all measurement results of comparable tests on UHPFRC dog-bones listed in [33]. CT scans of the dog-bone $\mathrm{T} 3.5 \mathrm{M}$ (t30) confirmed the particularly high homogeneous and parallel fiber alignment and distinct multicrack formation.
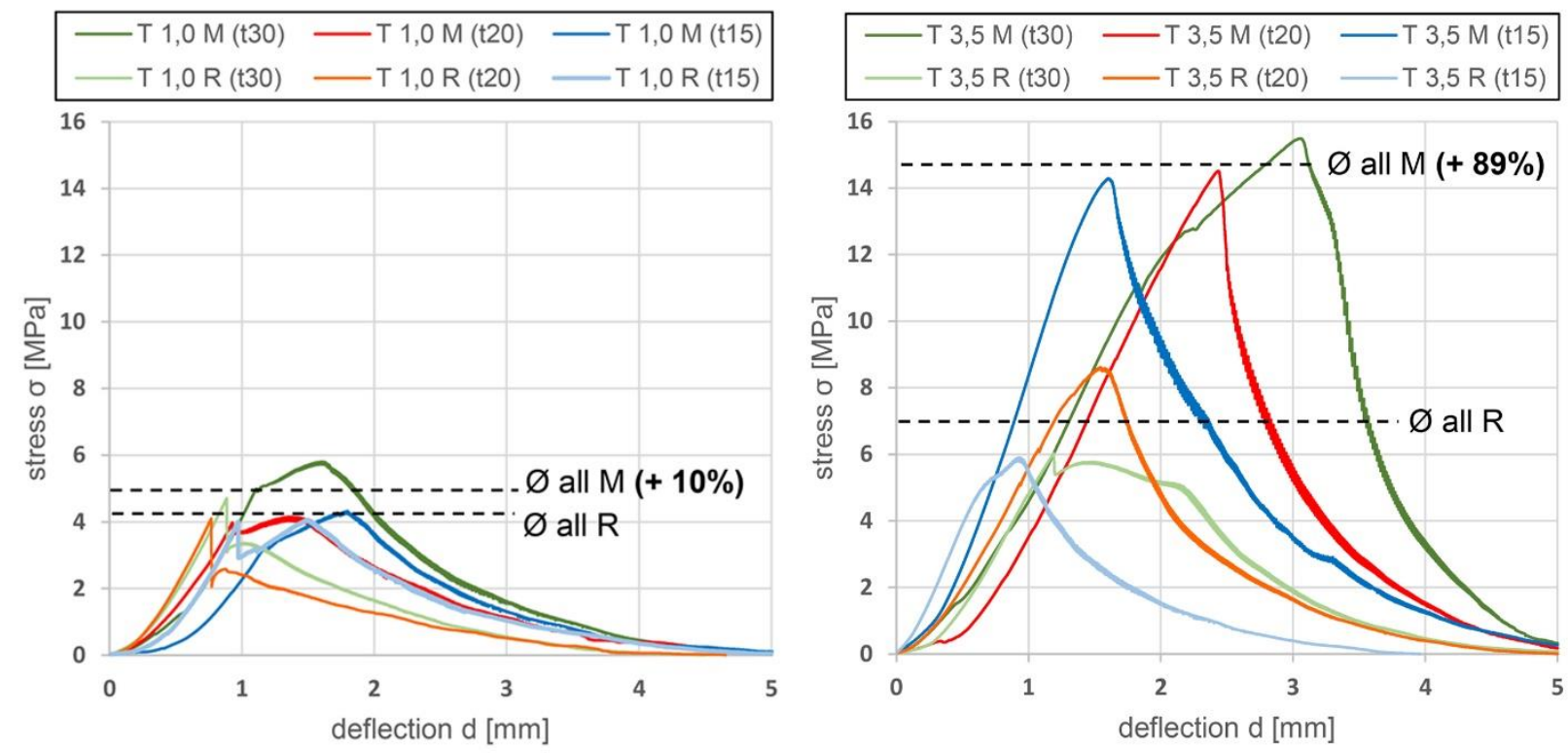

Figure 8. Stress-elongiation diagram of $M$ and $R$ series, fiber content $1 \%$ by volume (left);

stress-strain diagram of $\mathrm{M}$ and $\mathrm{R}$ series, fiber content $3.5 \%$ by volume (right)

Figure 9 shows the maximum tensile stresses reached in all 24 dog-bones tested in relation to the fiber content. It indicates that the fiber effectiveness of the $M$ series treated with the MFA process (MSF 8) increases overproportionally with increasing fiber content, and that the MVA process is particularly effective with higher fiber contents. However, this does not apply to the same extent to the treated dog-bones with recycled fibers. Here, despite the high fiber content, only a smaller mean increase in the maximum tensile stresses of $21 \%$ was recorded. 




Figure 9. Maximum tensile stresses in relation to fiber content of both MFA-treated (M) and non-treated $(R)$ dog-bones

\section{Economic and ecological savings potential}

On the basis of the centric tensile tests described above, it is possible to derive both economic and ecological savings potentials that result from the reduction of the fiber content. The magnitude of these savings depends to a large extent on the formulation of the UHPFRC under consideration. Figure 10 (left) shows the widely varying cost contribution of MSF to the concrete formulation used at a fiber content of $2.5 \%$ by volume. In the centric tensile tests, MSF of Scenario 1 (Stratec) and 4 (Genan) were used. In Scenario 2 and 3, the costs of comparable products from competitors were applied. The economic savings potential of the pure material costs of all four scenarios can be estimated as follows according to the test results:

The $40 \%$ reduction in fiber content achieved with the MFA process in the tests reduces the total cost of the UHPFRC by $24 \%$ in Scenario $1,18 \%$ in Scenario 2, and $12 \%$ in scenario 3. Despite the $80 \%$ increase in recycled fiber content required for equivalent performance of the UHPFRC compared to the $2.5 \%$ by volume fiber content of brand-new MSG 8 , the total cost of the UHPFRC would be reduced by $55 \%$ in scenario $1,38 \%$ in scenario 2 , and $20 \%$ in scenario 3.
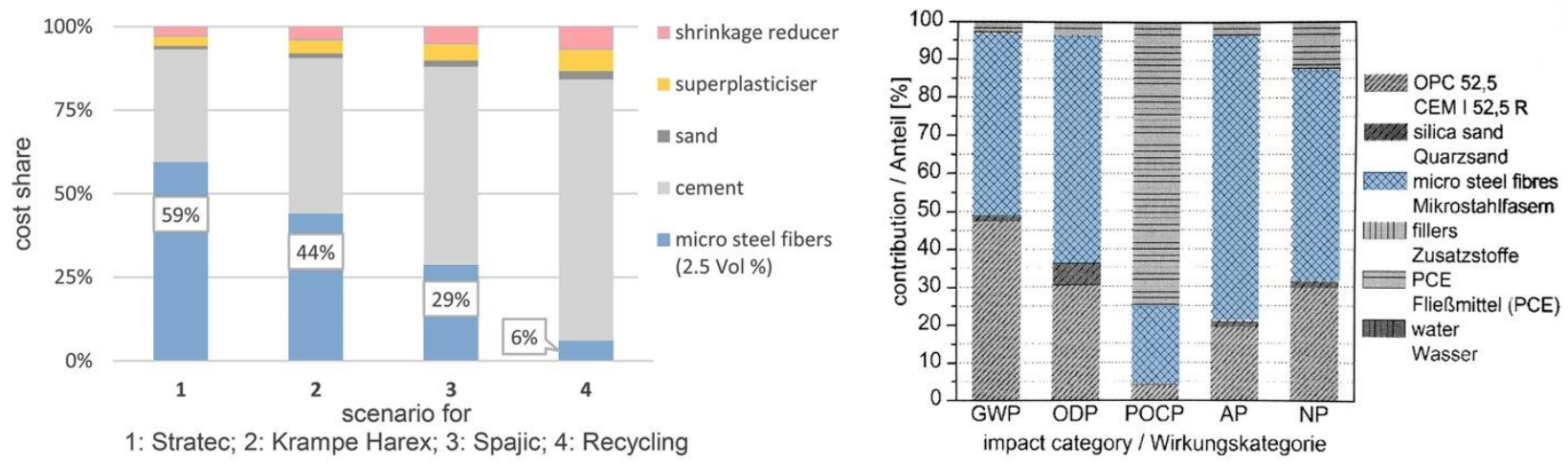

Figure 10. Cost share of $2.5 \%$ by volume of MSF from different suppliers (left);

Dominance analysis for the production of an average UHPC (from [34], colorized)

Figure 10 (right) compares the shares of the individual UHPFRC ingredients of an average UHPC in different impact categories. In four of the five impact categories, the share of MSF occupies more than $50 \%$ and ranks first, even ahead of cement. Thus, the magnitude of the environmental savings potential resulting from the reduction of the fiber content is compara- 
ble to the economic savings of scenario 1.

The sustainability analysis carried out in [34] divides the environmental impact of the production of MSF into the sub-processes wet drawing (40-50\%), production of the electrical steel $(30-40 \%)$ and hot rolling and stranding (2 - 20\%). Replacing new MSF with recycled MSF offers high environmental savings potential, as these fibers have already undergone all energy-intensive manufacturing processes. However, their non-ideal geomtrical properties in terms of length, diameter and straightness increase the necessary fiber content compared to uniform brandnew MSF. On the one hand, this resulted in poorer processability in the mixing process, and on the other hand, they therefore also showed lower performance in the transmission of tensile forces. However, since a satisfactory life cycle assessment of structures made of UHPFRC compared to structures made of normal concrete is mainly achieved by the potentially longer service life, the use of a higher fiber content is put into perspective.

\section{Conclusion and outlook}

The aim of the research described is to create the basis for the production of resourceefficient components with the aid of the controlled, automated magnetic distribution and orientation of MSF in UHPFRC. This defined arrangement of fibers significantly increases the efficiency of the fiber content used in a component and can thus lead to a large increase in performance or a significant reduction in the MFS used. As a result, in addition to improved processability of the UHPFRC, there is a large potential for saving ecological and economic resources, which can be significantly increased by using recycled MSF. In the future, the reproducible control of the process, which is to be ensured by using the latest developments in the field of automated production, will be decisive for an economical, practical construction application of the process, which has already been tested on a laboratory scale.

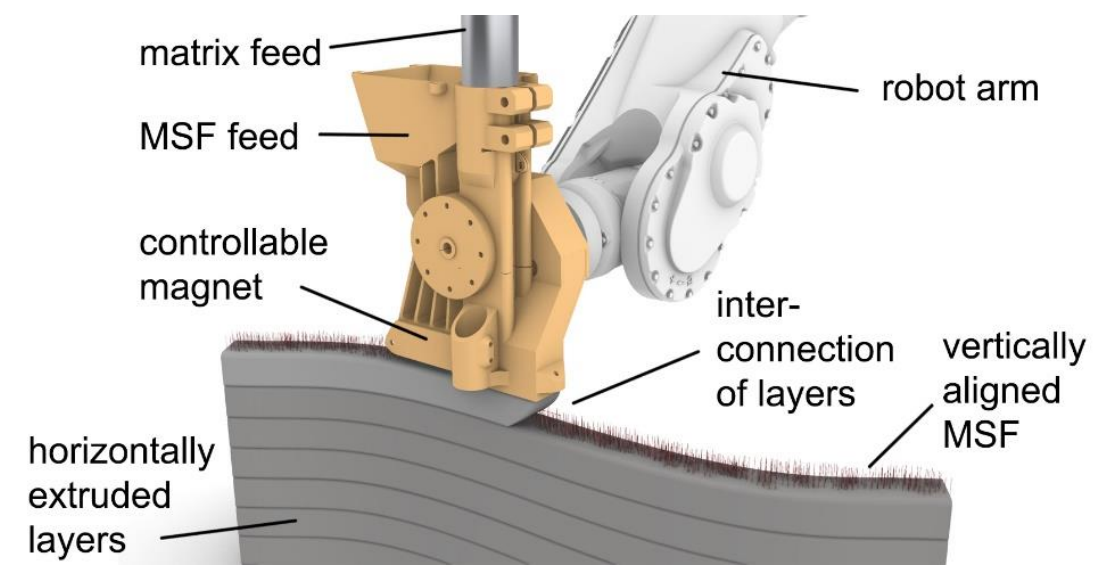

Figure 11. Illustration of a novel end effector for MFA integrated in layered extrusion

Beyond the application of the process for components made of UHPFRC cast in molds, the use of the principle of MFA in modified form is also possible in the additive manufacturing (AM) of concrete components. For example, initial trial runs of the technique in a combined process with Shotcrete 3D Printing (SC3DP) [35], developed at DBFL, have already shown promising results, providing clear indications of a possible novel reinforcement strategy for concrete components manufactured without formwork.

In addition, the application of the MFA process in other AM methods is currently being investigated at the ITE. The first end effectors for the integration of MFA into 3D concrete printing approaches based on layered extrusion and selective binding have already been produced and are now to be tested. In this context also the use of vertically oriented MSF is being investigated to avoid cold joints between extruded horizontal layers, as shown in Figure 11. One of the larger challenges in transferring the MFA process to AM construction methods without formwork is the higher viscosity of $A M$ concrete formulations compared to fresh 
UHPFRC. Therefore, an approach is presently pursued to reduce the viscosity of the matrix locally and for a short time during the printing process and thereby achieve a higher agility of the magnetically stimulated MSF.

The research field of magnetic fiber alignment thus has the potential to be extended beyond the application possibilities described to other innovative construction methods and contribute to the development of more resource-efficient concrete structures.

\section{Data availability statement}

All data generated or analysed during this study are included in this published article.

\section{Author contributions}

L. L. designed and performed the experiments, analysed the data and wrote the manusript. A. B. helped supervise the project. H. K. supervised the project.

\section{Competing interests}

The authors declare no competing interests.

\section{Acknowledgement}

The authors would like to thank the German Research Foundation (DFG) for funding the project "Fundamental investigations on robot-assisted magnetic distribution and alignment of microsteel fibers in thin-walled UHPFRC components".

\section{References}

1. M. Schmidt and E. Fehling, Eds., Entwicklung, Dauerhaftigkeit und Berechnung ultrahochfester Betone (UHPC): Forschungsbericht DFG FE 4971-1. Kassel: Kassel Univ. Press, 2005.

2. Nachrichten — SPP 1542. [Online]. Available: https://spp1542.tu-dresden.de/ (accessed: Sep. 30 2021).

3. L. Ledderose, S. Lehmberg, H. Budelmann, and H. Kloft, "Robotergestützte, magnetische Ausrichtung von Mikro-Stahldrahtfasern in dünnwandigen UHPFRC-Bauteilen," Beton- und Stahlbetonbau, vol. 114, no. 1, pp. 33-42, 2019. https://doi.org/10.1002/best.201800083

4. Ledderose, L.; Kloft, H.: Snap-fits made of reinforced concrete: From advanced manufacturing to novel applications. Conference: Proceedings of the IASS Symposium "Creativity in Structural Design". 16.-20.7.2018, Boston, 2018.

5. Ledderose, L.; Kloft, H.: Preliminary Investigations for Magnetic rearrangement of Steel Fibers in UHPFRC. Conference: Proceedings of the IASS Symposium „Shells, Membranes and Spatial Structures: Footprints.", 15.-19.9.2014, Brasil, 2014.

6. Ledderose, L.; Kloft, H.: Robot-aided rearrangement of steel fibres in UHPFRC via magnetic forces. Conference: Future Visions - Proceedings of the IASS Symposium 2015 \& ISOFF Symposium, 17.- 20.8. \& 16.- 17.8.2015, Amsterdam, 2015, paper No. IASS2015-517423, S. 12 - ISBN: 9789053630426.

7. S. Lehmberg, L. Ledderose, F. Wirth, H. Budelmann, and H. Kloft, "Von der Bauteilfügung zu leichten Tragwerken: Trocken gefügte Flächenelemente aus UHPFRC," Beton- und Stahlbetonbau, vol. 111, no. 12, pp. 806-815, 2016, doi: https://www.doi.org/10.1002/best.201600053. 
8. F. Fingerloos, J.-D. Wörner, and K. Bergmeister, Eds., Beton-Kalender 2013: Lebensdauer und Instandsetzung, Brandschutz. Berlin: Ernst \& Sohn, 2013.

9. DIN EN 10025-2:2019-10, Warmgewalzte Erzeugnisse aus Baustählen_- Teil_2: Technische Lieferbedingungen für unlegierte Baustähle; Deutsche Fassung EN_10025-2:2019, Berlin.

10. DIN EN 14889-1:2006-11, Fasern für Beton_- Teil_1: Stahlfasern_- Begriffe, Festlegungen und Konformität; Deutsche Fassung EN_14889-1:2006, Berlin.

11. S. Heinemeyer, Zum Trag- und Verformungsverhalten von Verbundträgern aus ultrahochfestem Beton mit Verbundleisten. Dissertation, RWTH Aachen, 2011.

12. C. Achilleos, D. Hadjimitsis, K. Neocleous, K. Pilakoutas, P. O. Neophytou, and S. Kallis, "Proportioning of Steel Fibre Reinforced Concrete Mixes for Pavement Construction and Their Impact on Environment and Cost," Sustainability, vol. 3, no. 7, pp. 965-983, 2011, doi: https://www.doi.org/10.3390/su3070965.

13. G. Graeff, K. Pilakoutas, K. Neocleous, and M. V. N. Peres, "Fatigue resistance and cracking mechanism of concrete pavements reinforced with recycled steel fibres recovered from post-consumer tyres," Engineering Structures, vol. 45, pp. 385-395, 2012, doi: https://www.doi.org/10.1016/j.engstruct.2012.06.030.

14. Genan, Genan - umweltfreundliches Altreifenrecycling. [Online]. Available: https://www.genan.de/ (accessed: Sep. 28 2021).

15. FEMM, HomePage: Finite Element Method Magnetics. [Online]. Available: https://www.femm.info/wiki/HomePage (accessed: Sep. 28 2021).

16. J. N. Luo and E. G. Sheu, "Physical Properties, Toxicity, and Physiological Effects of Magnets," in Magnetic Surgery, M. Gagner, Ed., Cham: Springer International Publishing, 2021, doi: https://doi.org/10.1007/978-3-030-73947-8

17. G. Bertram, Zum Verbund- und Querkrafttragverhalten von Spannbetonträgern aus ultra-hochfestem Beton. Zugl.: Aachen, Techn. Hochsch., Diss., 2012, 1st ed. Aachen: Eigenverl., 2012.

18. B. Frettlöhr, Bemessung von Bauteilen aus ultrahochfestem Faserfeinkornbeton (UHFFB). @Stuttgart, Univ., Diss., 2011. [Online]. Available: http://nbnresolving.de/urn:nbn:de:bsz:93-opus-71514

19. J. Bonzel and M. Schmidt, Verteilung und Orientierung von Stahlfasern im Beton und ihr Einfluß auf die Eigenschaften von Stahlfaserbeton. Beton 34 (1984), S. 463-470.

20. G. Bernier and M. Behloul, "Effet de l'orientation des fibres sur le comportement mécanique des BPR.," 1996.

21. T. Stengel, Effect of Surface Roughness on the Steel Fibre Bonding in Ultra High Performance Concrete (UHPC), Nanotechnology in Construction 3. Springer, Berlin, Heidelberg, 2009. 371-376, doi: https://www.doi.org/10.1007/978-3-642-00980-8_50

22. T. Pfyl, Tragverhalten von Stahlfaserbeton. Zugl.: Zürich, Eidgenössische Techn. Hochsch., Diss., 2002. Zürich: vdf Hochsch.-Verl. an der ETH, 2003.

I. Marković, High-Performance hybrid-fibre concrete: Development and utilisation. Zugl.: Delft, Techn. Univ., Diss., 2006. Delft: DUP Science, 2006.

23. T. Stengel, P. SchießI, C. Gehlen, and J. C. Walraven, Verbundverhalten und mechanische Leistungsfähigkeit von Stahlfasern in ultrahochfestem Beton. München, Technische Universität München, Diss., 2013. München: Universitätsbibliothek der TU München, 2013.

24. S. Stürwald, Rissentwicklung bei kombiniert bewehrten UHPC Balken. Kassel: Kassel Univ. Press, 2012.

25. S. Stürwald, "Versuche zum Biegetragverhalten von UHPC mit kombinierter Bewehrung; Forschungsbericht Fachgebiet Massivbau Fachbereich Bauingenieurwesen Universität Kassel," 2011.

26. DIN EN 196-3:2017-03, Prüfverfahren für Zement_- Teil_3: Bestimmung der Erstarrungszeiten und der Raumbeständigkeit; Deutsche Fassung EN_196-3:2016, Berlin.

27. Amira-Avizo 3D Software | Thermo Fisher Scientific. [Online]. Available: https://www.fei.com/software/avizo3d/\%C2\%A0\#gsc.tab=0 (accessed: Sep. 29 2021).

28. Fiji. [Online]. Available: https://imagej.net/software/fiji/ (accessed: Sep. 29 2021). 
29. J. Schnell, K. Schladitz, and F. Schuler, "Richtungsanalyse von Fasern in Betonen auf Basis der Computer-Tomographie," BUST, vol. 105, no. 2, pp. 72-77, 2010, doi: https://doi.org/10.1002/best.200900055

30. S. Lehmberg, "Herstellung und Eigenschaften von dünnwandigen, trocken gefügten Bauteilen aus ultrahochfestem faserverstärkten Feinkornbeton," Dissertation, TU Braunschweig, 2018.

31. SETRA, AFAC, Bétons fibrés à ultra-hautes performances, Recommandations, Revised edition, June 2013.

32. M. M. Reichel, Dünnwandige Segmentfertigteilbauweisen im Brückenbau aus gefasertem Ultrahochleistungsbeton (UHFB). Zugl.: Graz, Techn. Univ., Diss. Graz:, (Anhang 2) 2011.

33. T. Stengel, P. SchießI, „Sustainability analysisof UHPC using inventory analysis and impact assessment", in Nachhaltiges Bauen mit ultra-hochfestem Beton: Ergebnisse des Schwerpunktprogrammes 1182. M. Schmidt, E. Fehling, and S. Fröhlich, Eds, Kassel: Kassel Univ. Press, 2014.

34. Lindemann, H.; Gerbers, R.; Ibrahim, S.; Dietrich F.; Dröder, K.; Raatz, A.; Kloft, H.: Development of a shotcrete 3D-printing (SC3DP) technology for Additive Manufacturing of reinforced freedom concrete structures. First RILEM International Conference on Concrete and Digital Fabrication - Digital Concrete 2018, Zürich: Springer, 2018. 